\title{
EXAMINING SOCIAL PRESENCE IN ONLINE COURSES IN RELATION TO STUDENTS' PERCEIVED LEARNING AND SATISFACTION
}

\author{
Jennifer C. Richardson, Ph.D. \\ Assistant Professor of Educational Technology, Purdue University \\ BRNG Rm. 3142, 100 N. University Street \\ West Lafayette, IN 47906 \\ jennrich@purdue.edu
}

Karen Swan, Ph.D.

Research Center for Educational Technology

201 Moulton Hall

Kent State University

Kent, OH 44240

kswan@kent.edu

\begin{abstract}
Research has demonstrated that social presence not only affects outcomes but also student, and possibly instructor, satisfaction with a course [1]. Teacher immediacy behaviors and the presence of others are especially important issues for those involved in delivering online education. This study explored the role of social presence in online learning environments and its relationship to students' perceptions of learning and satisfaction with the instructor. The participants for this study were students who completed Empire State College's (ESC) online learning courses in the spring of 2000 and completed the end of semester course survey $(\mathrm{n}=97)$. A correlational design was utilized. This study found that students with high overall perceptions of social presence also scored high in terms of perceived learning and perceived satisfaction with the instructor. Students' perceptions of social presence overall, moreover, contributed significantly to the predictor equation for students' perceived learning overall. Gender accounted for some of the variability of students' overall perception of social presence, while age and number of college credits earned did not account for any of the variability.
\end{abstract}

\section{KEYWORDS}

Distance learning, Interaction, Social presence, Learning effectiveness, Student satisfaction, Faculty satisfaction, Perceived learning, Asynchronous learning, Computer-mediated learning, Computermediated communications 


\section{INTRODUCTION}

The educational community is finding itself on the edge of a new era of online learning. Online learning has been promoted as being more cost effective and convenient than traditional educational environments as well as providing opportunities for more learners to continue their educations. Online learning has been defined as any class that offers at least part of its curriculum in the online course delivery mode, or as a transmission of information and/or communication via the Internet without instructors and students being connected at the same [2]. Today, however, online learning is defined more clearly as any class that offers its entire curriculum in the online course delivery mode, thereby allowing students to participate regardless of geographic location, independent of time and place [3]. In other words, online education has progressed to the point where students no longer need to be able to meet face-to-face in order to complete a course.

Research in the area of online learning has demonstrated that the advantages offered by this environment are many $[4,5,6,7]$; especially the convenience and flexibility offered by the "anytime, anywhere" accessibility $[8,9,10,3,11,12]$. This catch phrase, widely used by institutions publicizing their online courses, means that students have access to courses and course materials 24 hours a day (time independent), regardless of location (place-independent), making them far more convenient than the traditional educational experience $[5,8,11,12]$. Another advantage of asynchronous learning is it allows students to reflect upon the materials and their responses before responding, unlike traditional classrooms $[5,8,11,12]$. Students also have the ability to work at their own pace, which is especially important for non-native speakers $[5,8]$. Moreover, the ability of personal identities to remain concealed means that all students, regardless of race, sex, disability, or appearance are on equal ground [5]. Finally, with the option of multiple representations of a concept embedded in an online course, students can store and retrieve information more effectively $[13,15]$.

Another characteristic of online learning that may be considered advantageous is that with the altered educational environment, the roles of students and instructors may also be transformed. The role of the instructor can be altered to become more akin to a facilitator than a lecturer, while the role of students can be altered by allowing them to become active learners $[3,5]$. This role transformation, however, is not the only issue facing instructors involved in the delivery of online courses; there is also the issue of how teacher immediacy behaviors and social presence are affected by the environmental transformation.

However, as with any learning environment, some disadvantages in comparison to other formats exist as well. Some critics claim that web-based or online learning is not as effective as traditional classroom learning because of its lack of face to face interactions [7, 16]. For example, Bullen conducted a case study examining student participation and critical thinking in a college level undergraduate course utilizing computer-mediated conferencing [16]. The case study showed that some students felt disconnected from others in this type of learning environment, citing lack of facial expressions and other features common to a traditional classroom environment. When considering the challenge of the effectiveness of online learning in comparison to traditional classroom learning, researchers have to ask themselves if it is really the physical presence of the instructor and students that is an essential element of learning; or, if not, then what element are critics denouncing? Perhaps we should really focus on the interactions that take place between students and instructors. Interactions can take place in an online environment as well as in a traditional classroom. Several studies have been conducted demonstrating that the very elements critics refer to as lacking are compensated for or even paralleled by paralanguage activities that occur in successful, interactive learning environments [17, 4, and 18]. Thus, it could be argued that the element that critics descry a diminishing of the social presence of the instructors and students. 
Social presence theory, a sub-area of communication theory, postulates that a critical factor of a communication medium is its "social presence," which is defined as the "degree of salience of the other person in the (mediated) interaction and the consequent salience of the interpersonal relationships" [19]. This is interpreted as the degree to which a person is perceived as "real" in mediated communication. Originally construed as an inherent feature of differing media, social presence may also be explored by examining a variety of issues which may contribute to the social climate of the classroom [20]. Consequently, it has been argued that social presence is a factor of both the medium and the communicators' perceptions of presence in a sequence of interactions [21]. The construct of social presence in this construction appears to have subsumed that of teacher immediacy by taking into consideration the fact that some media, such as computer, interactive video, audiotape, alter learning environments.

Short, Williams, and Christie, the initial investigators of social presence, hypothesized that users of communication media are in some sense aware of the degree of social presence of each medium and tend to avoid using particular interactions in particular media. Specifically, users avoid interactions requiring a higher sense of social presence in media which lack such capacity. Social presence, they contend, "varies among different media, it affects the nature of the interaction and it interacts with the purpose of the interaction to influence the medium chosen by the individual who wishes to communicate" [19].

Gunawardena and Zittle, researchers in the area of social presence and computer-mediated conferencing, argued that "in reviewing social presence research, it is important to examine whether the actual characteristics of the media are the causal determinants of communication differences or whether users' perceptions of media alter their behavior" [21]. They found that social presence could 'be cultured' among teleconference participants, a position different from the view that social presence is largely an attribute of the communication medium. Their research thus demonstrated that social presence is both a factor of the medium and of the communicators and their presence in a sequence of interactions [21].

Related to the research on social presence is the research conducted on teacher immediacy behaviors. The construct of teacher immediacy, originated by Wiener and Mehrabian's work, is a measure of the psychological distance that a communicator puts between themselves and the object of their communication [22]. The majority of research in instructional communication related to teacher immediacy behaviors has focused on teachers' use of verbal and nonverbal immediacy and the impact of those behaviors on students in traditional, face-to-face communication. For example, highly immediate behaviors have been associated with attitudinal changes, such as increases in student motivation to study $[23,24]$ and student satisfaction [1]. Researchers have investigated the effects of teacher immediacy on affective learning [25, 26, 27] and cognitive learning [25, 28, 29].

Teacher immediacy behaviors seem to take into account the same phenomena as social presence without the intermediating variable of media. Thus it may be that instructors and students involved in asynchronous communication develop a set of immediacy behaviors that "cultures" social presence in online courses as Gunawardena and Zittle suggest [21].

\section{METHODOLOGY}

\section{A. Purpose of the Study}

Although web-based learning is still a new domain, many businesses and educational institutions are 
moving forward in the arena and offering online courses, often in place of traditional learning environments. There is, however, little empirical evidence, that supports the design and management of successful web-based courses. Of the empirical evidence that does exist, very little of it examines the social aspects and/or benefits of online learning.

The purpose of this study was to explore the role of social presence in online learning environments. More specifically it examined the relationship among students' perception of social presence in online courses, students' perceived learning and their satisfaction with the instructor.

The following research hypotheses were tested:

a. Students' perceptions of social presence in online courses are related to their perceived learning and satisfaction with their instructor.

b. Students' perceptions of social presence in online courses are a predictor of their perceived learning.

c. Course activities perceived by students as having the highest level of social presence also have high levels of students' perceived learning.

d. Gender, age, and number of college credits earned are related to students' perceptions of social presence in online courses.

\section{B. Subjects}

The participants for this study were students who completed Empire State College's (ESC) online learning courses in the spring of 2000 and completed the end of semester course survey $(n=97)$. Data were not collected from students who enrolled but did not complete the course. The number of students who remained active throughout the semester was 369.

This particular sample was chosen because of the maturity of the online program available at ESC. ESC was a pioneer in the area of online education, being one of the first educational institutions to offer courses entirely via the World Wide Web. As such, the complications and complaints that generally plague newer online programs have been attended to at Empire State College, and thus, do not tend to contaminate students' perceptions of social presence in online courses. The ESC online course templates are now utilized within the entire SUNY Learning Network of online courses, consisting of over 1200 online courses created by various SUNY (State University of New York) colleges and universities.

The majority of participants reported being in the 36 to 45 age range, with a range of 19 to 63 years of age. Sixty-three percent of participants were female. Fifty-seven percent of participants indicated they were at the junior/senior undergraduate level according to credits earned, with a range of 3 to 260 credits completed. Forty-seven percent of participants reported that this was their first online course, fifteen percent of participants reported taking two online courses including the current course, and thirty-eight percent of students reported taking three or more online courses.

\section{Survey Instrument}

The survey instrument (see Appendix) used for this study is based on a social presence scale originally constructed by Gunawardena and Zittle for their research examining social presence as a predictor of satisfaction within computer-mediated conferencing environments [21]. The social presence scale was modified from the original in several ways. First, the language was modified to correspond with the SLN (SUNY Learning Network) environment rather than the GlobalEd environment it was originally intended for. The independent variables were modified via extension to focus on students' perceived learning. The scale was also modified so that individual course activities could be examined in view of the fact that the original scale examined the course from an overall perspective. 
The first section of the questionnaire consisted of general demographic items. These included gender, age, amount of online experience (one online course, two online courses, three or more online courses), and number of college credits earned.

Section Two of the survey consisted of 16 Likert-type items designed to assess students' overall perceptions of the course. These items used a six point response scale $(1=$ strongly agree to $6=$ strongly disagree) and prompted students to indicate the degree to which they agreed with each statement. Three variables were obtained from this section of the survey: students' satisfaction with their instructor, students' overall perceived learning, and students' overall perceived social presence, which was derived from students' average response to several social presence questions.

Section Three of the survey consisted of indicator statements related to social presence for each of the various types of course activities. Six types of activities were identified for this category, and they were selected based upon their natural occurrence in the SUNY Learning Network course templates. They included:

1. Lectures, Notes, Reading assignments

2. Written assignments

3. Individual projects

4. Group projects

5. Self-tests, module tests, final exam

For each of these course activities students were prompted to indicate the degree to which they agreed with each of the ten indicator statements using a six-point Likert-type scale ( $1=$ strongly agree to $6=$ strongly disagree). Students were allowed to answer "Not Applicable" if the course activity was not present in their online course. Twelve variables were obtained from this section of the survey (a perceived social presence and a perceived learning variable for each of the six course activities). Finally, at the end of Section two, students were also asked to answer two open-ended questions pertaining to their perceptions of benefits related to course activities in terms of their learning and satisfaction with them.

\section{Procedures}

A complete listing of students enrolled in the online courses and contact information was made available by the Center for Learning and Technology (CLT) at Empire State College. A mail-out, mail-back copy of the final questionnaire was sent to all students enrolled in the participating online courses $(n=369)$. In addition, a message including a quicklink to the online version of the survey was posted in a common area of the courses called the "bulletin board" where students also had the opportunity to fill out the survey online. This dual contingency was utilized to ensure a good return rate. Participants were given approximately two weeks from receipt of the survey to return the survey materials.

Each survey was accompanied by a cover letter that contained instructions to assist students in completing the survey, a statement as to the purpose of the study, and a confidentiality statement informing participants as to how the data would be used and reported. Anonymity of respondents was guaranteed because no individual could be identified regardless of how he or she chose to respond. Since all of the courses demonstrated a low return rate, students were mailed a second copy of the survey and asked again to respond either via the mailed-out survey or the online version of the survey. Students were given three weeks to respond to the survey. After the second mailing the return rate rose from $17 \%$ to $26 \%$ and the final sample size was 97 students out of a possible 369 students. 


\section{E. Research Design}

In this research study, a correlational design was utilized [38]. The continuous variables included students' perceived learning, students' perceived social presence, students' satisfaction with the instructor for the course overall, and students' perceived learning and perceived social presence for individual course activities. Correlations were also run between students' overall perceived social presence and demographic variables.

One limitation of this design is that while the correlational method can establish a relationship, it cannot establish a cause-effect relationship between variables that are correlated. As such, a relationship was established between students' perception of social presence and students' perceived learning. This, in turn, was followed by a direct entry regression of those variables in order to determine if students' perceptions of social presence was a predictor of students' perceptions of learning.

\section{ANALYSES}

\section{A. Students' overall perception of social presence, students' overall perceived learning, and students' overall satisfaction with instructor}

Correlations were calculated between three variables: students' overall perception of social presence, students' overall perceived learning, and students' overall satisfaction with instructor. Presented in Table 1 are the means, standard deviations and correlations among the variables. All assumptions of normality, linearity, and homogeneity were met.

\begin{tabular}{lcccc}
\hline \multicolumn{5}{c}{ Table 1. Means, standard deviations, and correlations (zero-order) (n=95) } \\
\hline Variable & $\mathrm{X}$ & $\mathrm{SD}$ & $\begin{array}{c}\text { Overall social } \\
\text { presence }\end{array}$ & $\begin{array}{c}\text { Overall perceived } \\
\text { learning }\end{array}$ \\
& 4.39 & 1.00 & & \\
\hline Overall social presence & 4.70 & 1.37 & $.68^{*}$ & $.73^{*}$ \\
Overall perceived learning & 4.39 & 1.74 & $.60 *$ & \\
Overall satisfaction with instructor & & & &
\end{tabular}

An examination of Table 1 shows that students' overall perceived learning yielded a correlation of .68 with students' overall social presence scores $\left(\mathrm{p}<.05 ; \mathrm{r}^{2}=.46\right)$; students' overall perceived learning yielded a correlation of $.73\left(\mathrm{p}<.05 ; \mathrm{r}^{2}=.53\right)$ with students' satisfaction with the instructor; and students' perception of social presence yielded a correlation of $.60\left(p<.05 ; r^{2}=.36\right)$ with students' satisfaction with the instructor.

These results have several implications:

1. Students reporting higher perceived social presence scores also perceived they learned more from the course than students with low perceived social presence scores. This indicates a relationship between social presence and perceived learning.

2. Students who were most satisfied with their instructors also believed they learned more from their courses than students who were less satisfied with their instructors. This indicates a relationship between instructor satisfaction and perceived learning.

3. Students with high overall social presence scores also indicated they were highly satisfied with their instructor. This implies that students' perceptions of social presence were related to the 
perceptions of their instructors as having a satisfactory online presence in terms of amount of interaction and/or quality of that interaction.

\section{B. Students' overall perception of social presence and students' overall perceived learning}

A standard direct entry regression was used to analyze the data. One continuous fixed variable served as the predictor, students' perception of social presence; the continuous random variable was students' overall perceived learning. See Table 1 above for the means, standard deviations, and correlations of the variables.

Results of the direct entry regression indicated that a significant predictor equation was established $(\mathrm{F}=78.83 ; \mathrm{df}=1,931 ; \mathrm{p}<.05)$. The correlation established was .68 with an $\mathrm{R}^{2}$ value of .46 . An examination of the results demonstrates that students' perceptions of overall social presence were a significant contribution to the equation.

\section{Students' overall perception of social presence and students' gender, age, and/or college credits earned}

Students' perceptions of social presence were also examined in terms of student demographic information obtained via the questionnaires. These items included students' gender, age, and college credits earned.

Correlations were calculated for each of the demographic items with students' overall perception of social presence. The analysis between gender and students' overall perception of social presence yielded a statistically significant correlation of .219 with an R2 value of .047 $(\mathrm{p}<.05)$ indicating that gender accounted for approximately $5 \%$ of the variability in students' overall social presence scores, with women perceiving a higher degree of social presence than men in this sample.

The correlational analysis for age and students' overall perception of social presence as well as the correlational analysis for college credits earned and students' overall perception of social presence earned were both statistically insignificant $(\mathrm{p}<.05)$; neither age nor number of college credits earned accounted for any of the variability in students' overall perception of social presence. This finding implies that students' perceptions of social presence are neither influenced by age or amount of college experience.

\section{Students' perception of social presence for individual course activities and their perceived learning for those activities}

Students' perceptions of social presence were also examined in terms of the types of individual activities available in the SUNY Learning Network (SLN) courses. The activities were divided into six categories based upon their natural occurrence in the SLN courses. The purpose of this exploration was to investigate the relationships between perceptions of social presence and perceived learning in individual course activities. Following in Table 2 are the findings for the individual course activities. 
Table 2. Summary of results for correlational analyses on individual course activities

\begin{tabular}{lccccc}
\hline \multicolumn{1}{c}{ Course activities } & $\mathrm{n}$ & $\begin{array}{c}\text { Mean score for } \\
\text { Social } \\
\text { Presence }\end{array}$ & $\begin{array}{c}\text { Mean score for } \\
\text { perceived } \\
\text { learning }\end{array}$ & $\begin{array}{c}\text { Correlation } \\
\text { between social } \\
\text { presence and } \\
\text { perceived learning }\end{array}$ & $\begin{array}{c}\text { Coefficient of } \\
\text { determination }\left(\mathrm{r}^{2}\right)\end{array}$ \\
\hline $\begin{array}{l}\text { Class discussions/ } \\
\text { Q and A areas }\end{array}$ & 94 & 4.58 & 4.70 & $.83^{*}$ & .69 \\
Group projects & 39 & 4.63 & 4.67 & $.80^{*}$ & .64 \\
Individual projects & 74 & 4.19 & 5.04 & $.55^{*}$ & .30 \\
Self-tests/module & 45 & 3.94 & 5.02 & $.50^{*}$ & .25 \\
$\quad$ tests/final exams & & & & & $.46^{*}$ \\
Written assignments & 93 & 4.12 & 5.06 & $.40^{*}$ & .16 \\
Lectures/notes/readings & 86 & 4.05 & 4.88 & & .21 \\
\hline$* \mathrm{p}<.01$ & & & & & \\
\hline
\end{tabular}

The mean score for social presence in class discussions and/or question areas was 4.58 and the mean score for perceived learning was 4.70 on a six point Likert scale ( $1=$ strongly disagree, $6=$ strongly agree). The analysis yielded a correlation of $.83\left(\mathrm{p}<.01, \mathrm{r}^{2}=.69\right)$. This indicates that social presence in class discussions and/or question areas accounted for approximately two-thirds of the variability in students' perceived learning for this activity. Students with high social presence also perceived high levels of learning in class discussions.

Similarly, students who perceived a strong social presence in group projects also perceived a high degree of learning from them. The mean score for social presence in group projects was 4.63 and the mean score for perceived learning was 4.67 on the Likert scale. The analysis yielded a correlation of $.80\left(\mathrm{p}<.01, \mathrm{r}^{2}=\right.$ .64). This indicates that social presence in group projects accounted for approximately two-thirds of the variability in students' perceived learning for this activity.

A correlation of $.55\left(\mathrm{p}<.01, \mathrm{r}^{2}=.30\right)$ was found between students' perceived learning and students' perceptions of social presence in individual projects. The mean score for social presence was 4.19 and the mean score for perceived learning was 5.04 on the Likert scale.

The mean score for social presence in self-tests, module tests, and/or final exams_was 3.94, and the mean score for perceived learning was 5.02 on the Likert scale. The analysis yielded a correlation of $.50(\mathrm{p}<.01$, $\mathrm{r}^{2}=.25$ ) between the two variables. This indicates that social presence in self-tests, module tests, and/or final exams accounted for one-quarter of the variability in students' perceived learning for this activity.

Considerably lower, yet still statistically significant correlations were also found between perceived learning and perceived social presence for the final two course activity categories. The mean score for social presence in written assignments was 4.12 and the mean score for perceived learning from written assignments was 5.06 on the Likert scale. The analysis yielded a correlation of $.46\left(\mathrm{p}<.01 ; \mathrm{r}^{2}=.21\right)$ 
between the two variables. This indicates that social presence in written assignments accounted for $21 \%$ of the variability in students' perceived learning for this activity. Students with high perceived learning in written assignments also perceived a strong social presence therein.

The mean score for social presence in lectures, notes, and/or reading assignments was 4.05 , and the mean score for perceived learning for those activities was 4.88 on the Likert scale. The analysis yielded a correlation of $.40\left(\mathrm{p}<.01, \mathrm{r}^{2}=.16\right)$. This indicates that social presence in lectures, notes, and/or reading assignments accounted for $16 \%$ of the variability in students' perceived learning for these activities.

The fact that significant correlations were demonstrated between social presence and perceived learning for each of the six individual activities for which students were asked to provide such scores indicates that the social presence of the instructor and/or other students was perceived by students as an integral aspect of their educational experience. It also indicates that social presence permeates those activities usually designated as individual activities. One possible explanation for this finding may be that students were asked to discuss individual projects and/or written assignments with their instructor or other students prior to completing the assignments, and this factor may account for students' perception of social presence during these activities.

\section{E. Qualitative Data}

The qualitative data collected from the open-ended questions reinforces the findings of the quantitative data. The open-ended questions followed section two of the survey and queried students about which activities they found most beneficial to their learning and why. Following are the frequencies and percentages collected from the open-ended questions, with students' $(n=82)$ indications of the activities they found most beneficial in Table 3 and the reasons for their selections in Table 4.

Table 3. Frequencies and percentages of students' responses to open-ended questions regarding beneficial activities of online courses (number of responses=157)

\begin{tabular}{lcc}
\hline \multicolumn{1}{c}{ Activities } & Frequencies & $\begin{array}{c}\text { Percentage } \\
\text { Identifying }\end{array}$ \\
\hline Written assignments & 49 & 31 \\
Class discussions/question areas & 39 & 25 \\
Readings & 24 & 15 \\
Lectures and notes & 17 & 11 \\
Individual projects & 14 & 9 \\
Self-tests/module tests/final exams & 8 & 5 \\
Group projects & 5 & 3 \\
\multicolumn{1}{c}{ Totals } & $157^{*}$ & 100 \\
\hline
\end{tabular}

${ }^{*}$ Students had the option of entering more than one selection; thus, percentages may not add up to $100 \%$.

Table 3 shows the activities students stated were most beneficial to their learning in online courses. Written assignments accounted for about one-third of these. Written assignments are the activities that allow students to apply or practice what they have learned in a course. Written assignments are also the activities in which students receive feedback from their instructors as to their degree of learning or understanding of a topic or concept. Table 4 below, which lists students' reasons for indicating particular 
activities as beneficial to their learning, gives feedback as the most frequently cited reason for perceiving activities as beneficial. Class discussions/question and answer activities in the courses accounted for $25 \%$ of students' selections for the most beneficial activity in their learning experience. This indicates, as does the quantitative data above, that students perceive the presence of others in their learning experience as an essential part of that experience. It should also be noted that less than $1 \%$ of students indicated that none of the class activities were beneficial.

Table 4. Frequencies and percentages of students' responses to open-ended questions regarding their reasons for choosing particular activities as most beneficial (number of responses $=126$ )

\begin{tabular}{lcc}
\hline \multicolumn{1}{c}{ Reason for selecting activity } & Frequencies & Percentage Agree \\
\hline Other students perspectives/feedback and/or interaction & 37 & 32 \\
Increased or expanded knowledge or & 34 & 30 \\
understanding and/or application of material & 25 & 13 \\
Instructor feedback/ guidance/facilitation & 13 & 11 \\
Clarification and/or reinforcement of material or & 13 & 11 \\
expectations from others & & 3 \\
Could work independently/did not have to rely & & 100 \\
on anyone else/self-pacing allowed for & & $126^{*}$ \\
students & &
\end{tabular}

* Students had the option of entering more than one selection

Table 4 shows students' stated reasons for selecting the activities listed in Table 3 as beneficial. Fifty-nine percent of participants indicated interaction, feedback, and other students' perspectives and/or acknowledgement as their reasons for selecting the activities they did as being the most beneficial to their learning. All of the aforementioned reasons relate to the presence of others, which corresponds with the quantitative findings.

\section{DISCUSSION}

This section discusses each of the findings of the analyses in the order of the hypotheses advanced.

\section{A. Hypothesis 1: Students' perceptions of social presence in online courses are related to their perceived learning and satisfaction with their instructor.}

Correlational analyses clearly showed a relationship between students' perceived social presence and students' perceived learning. This supports the hypothesized relationship between social presence and perceived learning, as well as providing indirect support for the notion that social presence is in some sense cultured, such as differences in social presence indicate something more than media effects. Such findings link the "culturing" of social presence in online courses to increased student perceptions of learning, a first step, at least, toward actual learning.

More problematic, perhaps, are correlations between overall social presence and overall instructor 
satisfaction, and between overall instructor satisfaction and overall perceived learning. Indeed, this latter correlation was slightly stronger than the correlation between perceived social presence and perceived learning, indicating that satisfaction with instructors factored at least as heavily in students' perceived learning. In fact, there was a relatively strong correlation between perceived social presence and instructor satisfaction.

Students' overall perception of social presence scores accounted for 35\% of the variability in students' overall satisfaction with the instructor. Students with high overall satisfaction with the instructor also had high overall social presence scores. These findings suggest that while students' perception of online presence of others was a good indicator of their satisfaction with the instructor, it was by no means the only indicator.

There is the possibility, however, that since this survey was not geared specifically to examine students' satisfaction with the instructor, there may have been some problem with isolating this concept. On the student survey there was only one question on students' satisfaction with the instructor versus multiple questions designed to generate a score for social presence, including two questions about interactions with the instructor. Thus, the social presence construct operationalized in the survey may have included some of the construct of instructor satisfaction. Qualitative data collected from open-ended questions at the end of the survey, indeed, indicated that students related their satisfaction with the instructors to the instructor's involvement with them in terms of guidance with course materials and assignments and/or feedback on assignments.

Another possibility is that the constructs of students' perceived social presence and students' satisfaction with the instructor might theoretically be related. Thus, it is necessary to determine if the overlap between these constructs is, in fact, theoretical in nature, or if it is a result of the design of the study and/or the instruments used to measure these constructs.

This finding, however, does correspond with the sociocognitive literature that states that learning is a social activity and that individuals learn more from their interactions with others than from reading materials alone [11, 30, 31, 32]. It also relates to the literature on teacher immediacy behaviors. Moore, Masterson, Christophel and Shea's study, for example, found significant positive correlations between teacher immediacy behaviors and students' ratings of instruction [1]. Students who perceived more frequent verbal and nonverbal immediacy behaviors in their teachers were more likely to give higher ratings to the overall quality of instruction and value of a course. More specifically, verbal and nonverbal immediacy behaviors were strong predictors of students' ratings of faculty/student interactions, lectures, and general communication. Hackman and Zane found that instructors who engaged in immediate behaviors such as encouraging involvement and offering individual feedback were viewed more favorably [33].

Similarly, Christophel also found that both students' perceptions of teacher immediacy and students' perceptions of trait and state motivation were positively associated with students' learning [24]. Kelley and Gorham [29], likewise found a positive relationship between teacher immediacy and cognitive learning at the short-term recall level, and Gorham and Zakahi [28] reported a positive relationship between students' and teachers' perceptions of teacher use of immediacy behaviors and of student learning outcomes.

All of the aforementioned literature relates to the presence of others, which corresponds with the quantitative findings of this study. This indicates that students perceive the presence of others in their 
learning experience as an essential part of it and that students' perceptions of satisfaction with an instructor are related to their perceptions of social presence.

\section{B. Hypothesis 2: Students' perceptions of social presence in online courses are a predictor of their perceived learning.}

While the correlational results tell us that there was a relationship between students' overall social presence and students' overall perceived learning, the standard direct entry regression analysis tells us that students' perceptions of social presence are a predictor of students' perceived learning in online courses. This indicates that the amount and/or intensity of social presence students' perceived in their online courses, from both their instructor and/or their peers, was directly related to their perceived learning in them.

This finding corresponds with the results of Gunawardena and Zittle's study that examined the possibility of social presence as a predictor of satisfaction within a computer-mediated conferencing environment [21]. Their study demonstrated that approximately $58 \%$ of the variance in student satisfaction with the CMC environment was contributed by social presence, suggesting that social presence was a strong predictor of satisfaction in a text-based computer conference. Analogously, Boverie, Nagel, McGee, and Garcia conducted a study to examine elements of learning styles, emotional intelligence, and social presence as predictors of distance education students' satisfaction needs [34]. The results showed that, of the three constructs, only social presence was a significant predictor of satisfaction.

These findings imply that instructors and designers of online courses need to take into account the mechanisms and/or behaviors by which social presence is conveyed in this environment and integrate those aspects into all such courses.

\section{Hypothesis 3: Gender, age, and number of college credits earned are related to students' perceptions of social presence in online courses.}

A significant correlation was found between gender and students' overall perception of social presence while correlations between both age and number of college credits earned were not statistically significant. The correlational analysis between gender and students' overall perception of social presence indicated that gender could account for $5 \%$ of the variability that occurred in the variable of students' overall perception of social presence, with women perceiving a higher degree of social presence than men in this study. This can indicate one of several possibilities which include: (1) the social presence scales used in this research may in some way be biased according to gender, (2) this finding may be specific to this particular sample, or 3) the reasoning for this finding may be related in some way to the larger literature base on gender that says that gender plays a role in our educational experiences [35, 36, 37]. Further research needs to be done on students' perceptions of social presence and gender in order to determine the reasons behind this finding.

\section{Hypothesis 4: Students' perceptions of social presence for individual course activities are related to their perceived learning for those activities.}

Significant correlations were demonstrated between social presence and perceived learning for each of the six individual activities for which students were asked to provide such scores, indicating that the social presence of the instructor and/or other students was perceived by students as an important factor in their educational experience.

When students were queried via open-ended questions as to the types of course activities that they perceived as being most beneficial to their learning, about one-third of students indicated written 
assignments while one-quarter of students indicated class discussions/question and answer activities. While class discussions/question and answer activities corresponds with the nature of social presence and its place in the online educational environment as discussed earlier, written assignments initially appears to oppose the findings of this research. Further inquiries into students' reasons for choosing the course activities, however, indicated otherwise. Fifty-nine percent of the survey participants indicated interaction, feedback, and other students' perspectives and/or acknowledgement as their reasons for selecting the activities they did as being the most beneficial to their learning.

These findings indicate that social presence permeates not only the activities generally designated as social activities but also those activities usually designated as individual activities. Several possible explanations for this finding emerged via the open-ended questions. These included: students being asked to discuss individual projects and/or written assignments with their instructor or other students prior to completing the assignments, and students perceiving the feedback they received for course assignments as part of that course activity.

These findings, moreover, coincide with the literature on online learning which states the "many-tomany" communication tool supports and facilitates active learning and collaboration, which, in turn, can increase motivation and satisfaction in online courses [11]. The literature also identifies interaction among students as critical in learning and cognitive development [31, 32]. Moreover, some theorists characterize learning as an interactive group process in which the learners actively construct knowledge and then build upon that knowledge through the exchange of ideas with others and the responses/feedback of others [11, 30].

As such, these findings need to be acknowledged and incorporated into the design and instruction of online courses. In other words, instructional designers and course instructors need to be made aware of these findings and then take appropriate measures to incorporate immediacy behaviors via discussions and/or activities in the online courses. As previously mentioned in Gorham's work, there are some immediacy behaviors that have been found in traditional classrooms which affected students' cognitive and affective outcomes; whether the same behaviors, however, would be effective in online courses is still another area of research which needs to be explored [25].

\section{E. Benefits and Limitations of the Study}

The major limitation of this study was that it only took into consideration the perceptions of the students who responded to the survey. There is currently no accountability for the perceptions of learning experiences and interactions with others in the online learning environment from the viewpoint of the students who did not respond to the survey or officially withdrew from the course before the end of the semester. Other limitations include the lack of randomization, manipulation, and control that characterize experimental studies. The randomization process in this case was beyond the researcher's control, as is customarily the case in educational settings, since the participants belong to an "intact group" and are administratively defined [38].

In addition, the sample used for this study was chosen for its ability to represent nontraditional students returning to school, rather than the traditional, undergraduate population. This point should be kept in mind when researchers or educators look to this body of research for indications of what to expect from their students or for its implications in their own educational environment. While online learning is becoming a popular mode of education particularly among returning students, a great number of students at Empire State College and other educational institutions also fall into the "traditional" category. 


\section{F. Significance of the Study}

Research has demonstrated that social presence not only affects outcomes but also student, and possibly instructor, satisfaction with a course [1]. Teacher immediacy behaviors and the presence of others are especially important issues for those involved in delivering online education. Instructors need to be aware of the impact that their immediacy behaviors and social presence or lack thereof may have on their students' satisfaction, motivation, and learning. The limited amount of empirical research in the area of social presence, the limited amount of empirical research in the area of online learning, and the lack of empirical research in the area of social presence related to online learning makes this study one of particular importance to the literature.

\section{CONCLUSIONS}

As the literature presented in this study demonstrates, interaction among participants is critical in learning and cognitive development [31,32]. Sociocognitive theorists describe learning as an interactive group process in which learners actively construct knowledge and then build upon that knowledge through the exchange of ideas with others $[11,30]$. These theories combined with the findings of this study indicate that there is a "better" model for online courses. The model should not only present the information and materials to students but also incorporate the social aspects of learning in both the design and instruction of online courses.

The immediate implications of this research extend into the realms of both research and practice. To begin with, more research needs to be conducted in the area of social presence, in both online educational environments and traditional educational environments. Research is needed to determine the extent that perceptions of social presence influence student satisfaction, student motivation and other attitudinal factors as well as students' actual cognitive and affective learning. From the instructors' perspective, research needs to be conducted to determine the extent of the influence of social presence on teacher effectiveness ratings and instructor satisfaction with courses taught.

Research also needs to be conducted in the vein of Gorham's study that looked at immediacy behaviors in traditional educational classrooms [25]. Perhaps if we can determine through observations, interviews, and analyses of online course documents what constitutes positive social presence behaviors, then more institutions and instructors can incorporate these behaviors into their courses. This, in turn, leads to the training of course instructors in methods that allow them to project positive social presence/immediacy behaviors as well as to incorporate or "culture" social presence among the participants/students in their courses [20]. 


\section{REFERENCES}

1. Moore, A., Masterson, J.T., Christophel, D.M., and Shea, K.A. (1996). College teacher immediacy and student ratings of instruction. Communication Education, 45, 29-39.

2. Berge, Z.L. and Collins, M. (1995). (Eds.) Computer-mediated communication and the online classroom. Cresskill, NJ: Hampton Press.

3. Harasim, L.N., Hiltz, S.R., Teles, L., and Turoff, M. (1995). Learning networks: A field guide to teaching and learning online. Cambridge, MA: The MIT Press.

4. Rourke, L., Anderson, T., Garrison, D.R., and Archer, W. (2001). Assessing social presence in asynchronous text-based computer conferencing. Journal of Distance Education, 14 (2).

5. Simonson, M., Smaldino, S., Albright, M., and Zvacek, S. (2000). Teaching and Learning at a Distance: Foundations of Distance Education. Upper Saddle River, NJ: Merrill.

6. Jiang, M. and Ting, E. (2000). A study of factors influencing students' perceived learning in a web-based course environment. International Journal of Educational Telecommunications, 6(4), 317-338.

7. Ward, M., and Newlands, D. (1998). Use of the Web in undergraduate teaching. Computers and Education, 31(2), 171-184.

8. Matthews, D. (1999). The origins of distance education and its use in the United States. T.H.E. Journal, 27 (2), 54-66.

9. Swan, K., Shea, P., Frederickson, E., Pickett, A. Pelz, W., and Maher, G. (2000). Building knowledge building communities: Consistency, contact, and communication in the virtual classroom. Journal of Educational Computing Research, 23 (4), 389-413.

10. Jiang, M. (1998). Distance Learning in a Web-based Environment. (Doctoral dissertation, University at Albany/SUNY, 1998). UMI Dissertation Abstracts, No. 9913679.

11. Harasim, L.M. (1990). Online education: Perspectives on a new environment. New York: Praeger.

12. Berge, Z.L. (1997). Computer conferencing and the online classroom. International Journal of Educational Telecommunications, 3 (1).

13. Kozma, R. (1987). The implications of cognitive psychology for computer-based learning tools. Educational Technology, XXVII (11), 20-25.

14. Morley, I. and Stephenson, G. (1969). Interpersonal and interparty exchange: A laboratory simulation of an industrial negotiation at the plant level. British Journal of Psychology, 61, 383.

15. Paivio, A. (1986). Mental representations: A dual-coding approach. New York: Oxford University Press.

16. Bullen, M. (1998). Participation and critical thinking in online university distance education. Journal of Distance Education 13(2), 1-32.

17. Picciano, A.G. (2002). Beyond student perceptions: Issues of interaction, presence, and performance in an online course. Journal of Asynchronous Learning, 6 (1). http://www.sloan-c.org/publications/jaln/v6n1/v6n1 picciano.asp.

18. Polhemus, L., Shih, L-F., Richardson, J.C. and Swan, K. (2000). Building an affective learning community: Social presence and learning engagement. Paper presented at the World Conference on the WWW and the Internet (WebNet); San Antonio, TX.

19. Short, J., Williams, E., and Christie, B. (1976). The social psychology of telecommunications. London: John Wiley and Sons.

20. Gunawardena, C.N. (1995). Social presence theory and implications for interaction and collaborative learning in computer conferences. International Journal of Educational Telecommunications, 1(2/3), 147-166.

21. Gunawardena, C.N. and Zittle, F.J. (1997). Social presence as a predictor of satisfaction within a computer-mediated conferencing environment. The American Journal of Distance Education, 11(3), 8-26.

22. Wiener, M. and Mehrabian, A. (1968). Language within Language: Immediacy, a channel in verbal communication. New York: Appleton-Century-Crofts. 
23. Christophel, D.M. and Gorham, J. (1995). A test-retest analysis of student motivation, teacher immediacy, and perceived sources of motivation and demotivation in college classes. Communication Education, 44, 292-306.

24. Christophel, D.M. (1990). The relationships among teacher immediacy behaviors, student motivation, and learning. Communication Education, 39, 323-340.

25. Gorham, J. (1988). The relationship between verbal teacher immediacy behaviors and student learning. Communication Education, 37, 40-53.

26. McCroskey, J.C., Sallinen, A., Fayer, J.M., Richmond, V.P., and Barraclough, R.A. (1996). Nonverbal immediacy and cognitive learning: A cross-cultural investigation. Communication Education, 45, 200-211.

27. Kearney, P., Plax, T.G., and Wendt-Wasco, N.J. (1985). Teacher immediacy for affective learning in divergent college classes. Communication Quarterly, 33(1), 61-74.

28. Gorham, J. and Zakahi, W.R. (1990). A comparison of teacher and student perceptions of immediacy and learning: Monitoring process and product. Communication Education, 39, 354-368.

29. Kelley, D.H. and Gorham, J. (1988). Effects of immediacy on recall of information. Communication Education, 37, 198-207.

30. Vygotsky, L. (1978). Mind in Society. Cambridge, MA: Harvard University Press.

31. Slavin. R. (1983). Cooperative Learning. New York: Longman, 1983.

32. Sharan, S. (1980). Cooperative Learning in Small Groups: Recent Methods and Effects on Achievement, Attitudes, and Ethnic Relations. Review of Educational Research, 50, 241-271.

33. Hackman, M.Z. and Walker, K.B. (1990). Instructional communication in the televised classroom: The effects of system design and teacher immediacy on student learning and satisfaction. Communication Education, 39, 196-206.

34. Boverie, P., Nagel, L., McGee, M. and Garcia, S. (1997). Learning styles, emotional intelligence and social presence as predictors of distance education student satisfaction. (ERIC Document Reproduction Service No. ED 410 810).

35. Acker, S. (1994). Gendered Education: Sociological Reflections on Women, Teaching and Feminism. Philadelphia: Open University Press.

36. Blackmore, J. and Kenway, J. (eds) (1993), Gender Matters in Educational Administration and Policy-a feminist introduction, Falmer Press, London

37. Nicholson, L. (1980). Women and Schooling. Educational Theory, 30(3): 225-234.

38. Gall, M.D., Borg, W.R., and Gall, J.P. (1996). Educational research (sixth edition). White Plains, NY: Longman Publishers.

\section{ABOUT THE AUTHORS}

Dr. Jennifer Richardson is a graduate of the University at Albany/SUNY and currently an Assistant Professor of Educational Technology in the Curriculum and Instruction Department at Purdue University. Her research interests include social aspects of learning in online environments, K-16 technology integration, and professional development related to educational technology.

Email: jennrich@purdue.edu

Dr. Karen Swan is the RCET Research Professor in the Research Center for Educational Technology at Kent State University. She is widely published in the area of technology and learning and is currently particularly interested in online learning and technology-rich classroom environments. She is the Learning Effectiveness Editor for the Sloan Consortium.

Email: kswan@kent.edu 


\section{ACKNOWLEDGEMENTS}

The authors would like express their appreciation to Empire State College, specifically the CLT Staff, and especially Evelyn Ting, for making this research possible. 


\section{APPENDIX}

Name (*optional)

Course Name (*Required)

Course Instructor (*Required)

Age__ Gender___ Approximate number of college credits
completed

Online Experience:

This is my first online course

I have taken two online courses including this course.

I have taken more than two online courses including this course.

Part I. Your responses to the following questions should reflect your online experience overall for this particular course. For the following questions please circle the number which best reflects your opinion in the answer column to the left of the question.

$(1=$ strongly agree, $2=$ agree, $3=$ somewhat agree, $4=$ somewhat disagree, $5=$ disagree, $6=$ strongly disagree $)$

Questions

Online or web-based education is an excellent medium for social interaction.

I felt comfortable conversing through this medium.

I felt comfortable introducing myself in this course.

The introductions enabled me to form a sense of online community.

The instructor created a feeling of an online community.

I felt comfortable participating in course discussions.

The instructor facilitated discussions in the course

I felt comfortable interacting with other participants in the course.

I felt that my point of view was acknowledged by other participants in the course.

I was able to form distinct individual impressions of some course participants.

My level of learning that took place in this course was of the highest quality.

Overall this course met my learning expectations.

Overall the instructor for this course met my expectations.
SA

$\begin{array}{llllll}1 & 2 & 3 & 4 & 5 & 6 \\ 1 & 2 & 3 & 4 & 5 & 6 \\ 1 & 2 & 3 & 4 & 5 & 6 \\ 1 & 2 & 3 & 4 & 5 & 6 \\ 1 & 2 & 3 & 4 & 5 & 6 \\ 1 & 2 & 3 & 4 & 5 & 6 \\ 1 & 2 & 3 & 4 & 5 & 6 \\ 1 & 2 & 3 & 4 & 5 & 6 \\ 1 & 2 & 3 & 4 & 5 & 6 \\ & & & & & \\ 1 & 2 & 3 & 4 & 5 & 6 \\ 1 & 2 & 3 & 4 & 5 & 6 \\ 1 & 2 & 3 & 4 & 5 & 6 \\ 1 & 2 & 3 & 4 & 5 & 6\end{array}$


Part II. The questions in the following two tables examine the specific activities within your course. Table 1 includes: Meet Your Classmates and Bulletin Board, Class Discussions and Question and Answer Areas, and Lectures/Notes/Readings. Table 2 includes: Written Assignments, Individual Projects, Group Projects, and Self-Tests/Module Tests/ Final Exams. For each of the following statements please type the number which best reflects your experience for this course in the box that corresponds with each activity and indicator. Please note that if your course does not contain a particular activity then you should respond with an "NA" for not applicable.

Table 1

$1=$ strongly agree, $2=$ agree, $3=$ somewhat agree, $4=$ somewhat disagree, $5=$ disagree, $6=$ strongly disagree, NA=not applicable

\begin{tabular}{|l|l|l|l|}
\hline \multicolumn{1}{|c|}{ Indicator Statements } & \multicolumn{2}{|c|}{ Course Activities } \\
\hline \multicolumn{1}{|c|}{$\begin{array}{l}\text { Meet Your } \\
\text { Classmates, } \\
\text { Bulletin Board }\end{array}$} & $\begin{array}{c}\text { Class Discussions, } \\
\text { Question Areas }\end{array}$ & $\begin{array}{c}\text { Lectures, } \\
\text { Notes, Reading } \\
\text { Assignments }\end{array}$ \\
\hline $\begin{array}{l}\text { The quality of learning for this activity was } \\
\text { excellent. }\end{array}$ & & & \\
\hline $\begin{array}{l}\text { I felt comfortable conversing through this medium } \\
\text { for this activity }\end{array}$ & & & \\
\hline $\begin{array}{l}\text { Online or web-based education is an excellent } \\
\text { medium for social interaction as demonstrated by } \\
\text { this activity. }\end{array}$ & & & \\
\hline $\begin{array}{l}\text { This activity enabled me to form a sense of online } \\
\text { community. }\end{array}$ & & & \\
\hline $\begin{array}{l}\text { The instructor created a feeling of online } \\
\text { community during this activity. }\end{array}$ & & & \\
\hline I felt comfortable participating in this activity. & & & \\
\hline This activity was facilitated by the instructor. & & & \\
\hline $\begin{array}{l}\text { I felt comfortable interacting with other } \\
\text { participants in this activity. }\end{array}$ & & & \\
\hline $\begin{array}{l}\text { My point of view was acknowledged by other } \\
\text { participants during this activity. }\end{array}$ & & & \\
\hline $\begin{array}{l}\text { I was able to form distinct individual impressions } \\
\text { of some course participants during this activity }\end{array}$ & & & \\
\hline
\end{tabular}


Table 2

$1=$ strongly agree, $2=$ agree, $3=$ somewhat agree, $4=$ somewhat disagree, $5=$ disagree, $6=$ strongly disagree, NA=not applicable

\begin{tabular}{|c|c|c|c|c|}
\hline \multirow[b]{2}{*}{ Indicator Statements } & \multicolumn{4}{|c|}{ Course Activities } \\
\hline & $\begin{array}{c}\text { Written } \\
\text { Assignments }\end{array}$ & $\begin{array}{l}\text { Individual } \\
\text { Projects }\end{array}$ & Group Projects & $\begin{array}{l}\text { Self-Tests, } \\
\text { Module Tests, } \\
\text { Final Exam }\end{array}$ \\
\hline $\begin{array}{l}\text { The quality of learning for this activity } v \\
\text { excellent. }\end{array}$ & & & & \\
\hline $\begin{array}{l}\text { I felt comfortable conversing through th } \\
\text { medium for this activity }\end{array}$ & & & & \\
\hline $\begin{array}{l}\text { Online or web-based education is an } \\
\text { excellent medium for social interaction } \\
\text { demonstrated by this activity. }\end{array}$ & & & & \\
\hline $\begin{array}{l}\text { This activity enabled me to form a sense } \\
\text { online community. }\end{array}$ & & & & \\
\hline $\begin{array}{l}\text { The instructor created a feeling of online } \\
\text { community during this activity. }\end{array}$ & & & & \\
\hline $\begin{array}{l}\text { I felt comfortable participating in this } \\
\text { activity. }\end{array}$ & & & & \\
\hline This activity was facilitated by the instru & & & & \\
\hline $\begin{array}{l}\text { I felt comfortable interacting with other } \\
\text { participants in this activity. }\end{array}$ & & & & \\
\hline $\begin{array}{l}\text { My point of view was acknowledged by } \\
\text { other participants during this activity. }\end{array}$ & & & & \\
\hline $\begin{array}{l}\text { I was able to form distinct individual } \\
\text { impressions of some course participants } \\
\text { during this activity }\end{array}$ & & & & \\
\hline
\end{tabular}

Which of the activities listed in Tables 1 and 2 was most beneficial to your learning and why?

Which of the activities listed in Tables 1 and 2 was most satisfying to you and why? 
Part III: $\quad$ Please answer the following questions.

1. How satisfied were you with this course? For example, were your goals and/or expectations met? Please explain (e.g. were the course activities and assignments appropriate, was content wellorganized, etc.).

2. What was your reason for taking the course in the online delivery format (e.g. like to interact with fellow students online, only offered online, etc.)?

3. Which aspect of this course was most beneficial to you and why? (This can include different types of course activities, types of interactions, etc.)

4. How much interaction have you had with your instructor (e.g. moderate, sufficient, lacking)? Please describe.

5. In relation to student-to-student interaction, would you say the type and amount of student participation was adequate for this course? Based on these observations, are there any recommendations you would make to the SUNY Learning Network?

6. Additional Comments: 